\title{
'Off the Radar:' the Framing of Speech, Language and Communication in the Description of Children with Special Educational Needs in Literacy
}

\author{
Maria A. Mroz \\ Correspondence: Maria A. Mroz, University of Newcastle, United Kingdom
}

Received: April 2, 2014

doi:10.11114/jets.v2i3.382

\author{
Accepted: April 18, 2014 \\ Online Published: June 10, 2014 \\ URL: http://dx.doi.org/10.11114/jets.v2i3.382
}

\begin{abstract}
This paper considers how pre-service primary teachers in England (trainees) are supported to work with children with special educational needs (SEN) using a personalized learning task. The focus, in particular, considers how speech, language and communication skills are foregrounded in the reports describing children with moderate learning difficulties including difficulties with literacy. The context recognizes the importance of pupils' spoken and receptive language development and the prevalence of children categorized as having speech, language and communication needs (SLCN) and the educational, social and emotional impact of this disability. However analysis of sixty five reports identified only four children with SLCN. In contrast eighteen 5-7 year old children were identified who were struggling with literacy. Analysis was conducted on this sub-set due to the close links between reading development and spoken language skills. The analysis explored the question 'what do trainees' descriptions of literacy reveal about their understanding of speech, language and communication?' Results revealed that speech, language and communication skills were referred to only briefly and with some limitations in understanding. Further analysis explored the task design and considered to what extent it supports trainees in referring to knowledge about speech, language and communication in practice. The article concludes that the personalized learning task could be adapted to ensure greater development of knowledge of speech, language and communication and the role of teacher talk. It considers the challenges posed for mentoring where the prevailing social semiotics of the classroom emphasizes performativity (Ball, 2003) over a more holistic view of children.
\end{abstract}

Keywords: trainee teachers, special educational needs, speech, language, communication

\section{Overview and Background Context}

Pre-service teachers in England (hereafter referred to as trainees) embark on their training program understanding that inclusion is central to school practice and that the class teacher is responsible for the progress made by all pupils. Thus trainees need to develop, with appropriate advice and support, the necessary skills and knowledge to teach all children including those with special educational needs (SEN). The article is therefore concerned with an important issue; how trainees are supported to work with children with SEN. The article focuses on one approach tailored to support PGCE (Post Graduate Certificate in Education) trainees; 'A special educational needs personalized learning task for PGCE courses'(hereafter referred to as 'the personalized learning task', Teacher Development Agency, 2008, 2012).

My role within this higher education institution is as a lecturer in Education on the Primary PGCE course. Prior to my current position I had been both a primary teacher and a Special Educational Needs Co-coordinator and before that a speech and language therapist. Thus my interaction with the personalized learning task was both borne of, and mediated through, an awareness of the needs and the numbers of children with language delay and speech, language and communication needs (SLCN). My professional background directly influences my interactions with the PGCE trainees.

\subsection{Special Educational Needs and Inclusion}

The education of children with special educational needs has continued to be a priority in the teaching profession in England moving from integration to inclusion in accordance with the Salamanca Agreement (UNESCO, 1994). For the purpose of this paper inclusion is defined as "providing a framework within which all children - regardless of ability, gender, language, ethnic or cultural origin - can be valued equally, treated with respect and provided with real opportunities at school." (Thomas and Loxley, 2007, p. 124). The introduction of the SEN Code of Practice (Department for Education and Schools, 2001) provided a staged model for how pupils with SEN are identified and supported. The ongoing 'inclusion agenda' places a firm emphasis on 'the need for well-trained teaching (and other 
staff) who know how to support children with additional needs, including SEN." (Department for Education, 2010a p.26). An expected outcome from this policy document is that teachers will be better equipped to identify children with SEN.

\subsection{Speech, Language and Communication and the Interaction with SLCN}

The article considers how speech, language and communication are foregrounded in the education of children with SEN in literacy. The challenges faced by, and the impact on society of, pupils with SLCN were reiterated in The Bercow Report: a review of services for children and young people (0-19) with speech, language and communication needs' (Department for Children Schools and Families, 2008). This report called for, and has had some impact upon, the role of schools in developing the expressive and receptive language skills of pupils with SLCN. It should be acknowledged that the terminology describing and categorizing children's learning in respect of their first language is confusing (see Dockrell et al, 2012). For example the term 'speech, language and communication need' is used in two different ways within English education practice. The Bercow Report (2008) employed a broad definition which includes all children with speech, language and communication needs, both where this is the child's primary difficulty but also where these needs are deemed to be secondary to other developmental issues such as, for example, hearing impairment or cognitive impairment. This definition will include children who are 'language delayed'. The second narrower definition relates to those children formally identified as having a speech, language and communication need (Department for Education, 2011) whose primary need lies within speech, language and communication whilst excluding children on the autistic spectrum. The focus on SLCN and speech, language and communication development is justified because within primary schools language delay is the most common childhood disability (Law, Boyle, Harris, Harkness \& Nye, 2000). This disability has potentially far reaching and stark consequences for children's social, emotional, behavioral and academic well-being (Botting and Conti-Ramsden, 2000; Clegg, Hollis, Mawhood \& Rutter., 2005; Conti-Ramsden, Knox, Botting \& Simkin, 2002; Lindsay, Dockrell, \& Strand, 2007; Stothard, Snowling, Bishop, Chipchase \& Kaplan, 1998). It is important to note that within the population of children with SLCN there are issues of under-identification (Meschi, Micklewright, Vignoles \& Lindsay, 2012). Thus although international prevalence rates suggest $7.4 \%$ of school-aged children have a specific speech, language and communication need (Tomblin, Records, Buckwalter, Zhang, Smith \& O'Brien, 1997) only 3\% have been identified in the current English education system.

There has also been a developing concern about the language development of all pupils, rather than just those with particular needs, and the links between language competence and later educational outcomes (The Communication Trust, 2013). A further factor that the renewed focus on speech, language and communication has caused to re-emerge is the issue of class and the potentially 'impoverished language' of pupils from lower SES groups (see Grainger, 2013, for a critique).

\subsection{Classroom 'Talk' and Its Role in Learning}

Research that recognizes the limiting factor inadequate spoken communication has on pupil learning (Stothard et al, 1998) adds further support for the long recognized understanding that that language is central for learning for all pupils (Barnes 1976, Galton, Hargreaves, Comber \& Wall, 1999, Alexander, 2008, Bercow, 2008). Research concludes that teachers, can, through their classroom discourse, play a vital role in developing the speech, language and communication skills of all pupils (Mercer, Dawes, Littleton \& Wegerif, 2010). The term oracy (Wilkinson, 1965) is useful here and is currently defined as "what the school does to support the development of children's capacity to use speech to express their thoughts and communicate with others in education and in life" (Alexander, 2012, p.10) and thus encapsulates the teacher's role in the teacher-pupil interaction. The current landscape in terms of the development of children's spoken language in schools is highly variable with a number of alternative approaches co-existing within Local Authorities, schools and classrooms. These include Alexander's focus on dialogic teaching in which he defines dialogic interaction thus, "Children are exposed to alternative perspectives and required to engage with another person's point of view in ways that challenge and deepen their own conceptual understandings" (Alexander, 2008p. 4). Alternative approaches to developing pupils' spoken language in schools include the Kagan approach to classroom instruction (Marzano, Pickering \& Pollock, 2001) and Mercer et al's 'Thinking Together Project' (2010). Alexander (2010), perhaps in anticipation of the variation in approaches available, proposed that each primary school should have an oracy expert who would be responsible for the development of teachers' classroom talk and of pupils' speaking and listening skills, thus affording both a high priority- this proposal has not, to date, been supported.

Latterly there has been a further renewed focus on communication resulting from changes to the Ofsted (Office for Standards in Education) Framework for School Inspection (Ofsted, 2012a). This now includes a new judgement on, how well teaching enables pupils to develop skills in reading, writing, communication and mathematics" (p.15); "how well pupils develop a range of skills, including reading, writing, communication and mathematical skills, and how well they apply these across the curriculum"' (p.14, emphasis added). The inclusion of communication alongside reading and 
writing in the framework is significant as it reiterates the important role of communication skills in the continued drive to raise standards in literacy for all pupils. Research evidence has accumulated that demonstrates the important role that language plays in the development of reading. Goswami and Bryant, $(2010$, p.97) found that "language development, along with perceptual and spatial development, underpins children's progress in reading".

Thus we have an educational context in which it is recognized that well-developed verbal language skills are deemed to be central to learning and that 'teacher- talk' should have a crucial role in this development through, for example, the dialogic repertoire (Alexander, 2012) teachers are able to utilize in the classroom. At the same time a particular spotlight has been placed by Government and others (for example The Communication Trust) on the role of spoken language in the development of literacy as the impact of 'poor language skills' has particular implications for literacy (Conti-Ramsden \& Durkin, 2008).

\subsection{Training for Personalized Learning}

Within initial teacher education (ITE) the priorities for working with pupils with SEN echo those within schools. However Steer (2009) reports gaps in trainees' understanding of how to support pupils with SEN. Inevitably the experiences in working with SEN pupils afforded to trainees are necessarily constrained due to limitations of time and opportunity within an approximately forty four week program (with twenty four weeks spent within school settings). In order to address the importance placed on SEN and inclusion the following bespoke task was developed by the now disbanded Teacher Development Agency (TDA, 2008, 2012, now housed under the University of Exeter and the Institute of Education's websites): 'A special educational needs personalized learning task for PGCE (Post Graduate Certificate in Education) courses'('the personalized learning task'). The term 'personalization', which is central to the task under discussion, has many definitions. For example, the Teaching and Learning in 2020 review group (2006) included the individual nature of personalized learning, but aligned this with participation, by defining it as:

...taking a highly structured and responsive approach to each child's and young person's learning, in order that all are able to progress, achieve and participate. It means strengthening the link between learning and teaching by engaging pupils - and their parents - as partners in learning. (p.6).

However within the Framework for Personalised Learning, (TDA, 2008, 2012) trainees are guided towards a practical model for personalisation based on Wedell (1993). This model describes a cycle of assessment, decision making, teaching and review that are involved in ensuring pupils' needs are met; this cycle is part of each school's practice in England and is integral to the SEN Code of Practice.

An important factor to acknowledge is that the task is compulsory for our trainees and that they have been told it can be used to provide evidence towards Standard 5 "Adapt teaching to respond to the strengths and needs of all pupils" (p.1 Department for Education 2012). This standard is compartmentalized into key bullet points which includes, "have a clear understanding of the needs of all pupils, including those with special educational needs" which trainees may interpret as an atomized list to address. The writing framework provided itself further supports this 'checklist' approach with key headings provided. There is a danger associated with indicating that the task can be used to meet a particular standard because it could contribute to the culture of performativity (Ball 2003) which is "characterised by high stakes testing, attainment driven school and national league tables; a dominant Ofsted inspection regime and school-generated 'self surveillance' which leads to the micro-management of teachers' performance” (Lofthouse and Thomas, 2014, p.1).

Within the English teacher education system it is understood that tasks like this one, presented to trainees, will then need to be mediated by staff in schools who will be actively involved in supporting at the very least the organizational demands. Furthermore there is an assumed understanding by our Higher Education Institutions generally that the teachers will mentor trainees and as part of that process discuss pedagogy and reflect explicitly on their own practice.

\subsection{The Personalised Learning Task}

The personalised task requires trainees to:

- Find out in detail about the educational needs of a pupil with SEN in a particular subject area,

- Learn more about the origins of educational needs and the interactions between the pupil's difficulties/ disabilities and environmental factors,

- Learn how to assess the additional educational needs of a pupil in a particular subject area,

- Develop their skills in planning and teaching to meet the pupil's identified educational needs, monitoring the progress that the pupil makes as a result, and,

- Form a teaching relationship with a pupil with a SEN/ disability and gain experience of how they learn (www.dera.ioe.ac.uk Task brief, p.27). 
The pupil identified by the school as suitable for the task must be an individual who needs greater support than is provided by differentiated work within the classroom. Trainees are expected to draw on evidence from teaching colleagues and other staff as it is common practice for Teaching Assistants (TAs) to provide group or individual support for pupils with SEN under the guidance of the teacher or another professional. In addition the trainees carry out their own observations and scrutinize reports and analyze information which is summarised using 'A checklist of environmental and pupil factors that may impact on learning' (TDA, $2012 \mathrm{http} / / /$ www.education.exeter.ac.uk/projects $\mathrm{p}$. 45-46, 'the checklist' - see appendix 1). An intervention is then planned for the child based on the information gathered and, 'notes and records you will have kept while doing this task will be integrated and analysed in writing this report' (p.32 Task brief for trainees TDA 2012). The task itself and the associated report are heavily prescribed and scaffolded through the provision of detailed guidance (Writing up the task, TDA 2012,http://www.education.exeter.ac.uk/projects Framework for Personalised pp 32-33, see appendix 2).

\subsubsection{The 'Personalised Learning Task' in This Particular Context}

Prior to completing the task in school, trainees, in common with their peers throughout ITE, had attended a number of lectures and workshops outlining legislation and key principles and practice of working with pupils with SEN. They had also attended workshops on: working with pupils with SLCN, hearing impairment, visual impairment, dyslexia, physical needs, emotional and behavioral difficulties and autistic spectrum disorder. A factor relevant to later discussion is the fact that these particular trainees had all completed a reading and speaking and listening assignment in their first teaching placement. This assignment focused on one typically developing child and each trainee produced both a reading and a speaking and listening profile. The latter was compiled based on observations of the child in a variety of school contexts and the completed profile summarized the pupil's expressive and receptive language skills, including reference to language structure, vocabulary, language use and comprehension of spoken language. This information was then used to plan an intervention focused on reading, but which drew on their knowledge of the child's speaking and listening skills.

\section{Method and Data and Analysis}

\subsection{Participants}

The data for this analysis were drawn from trainee teachers $(n=84)$ enrolled on a PGCE primary course based (20112012) in a Higher Education Institution in the North East of England. The personalised learning task was carried out whilst the students were engaged in their third and final 8 week teaching placement prior to being recommended for initial entry into the teaching profession.

\subsection{Sample}

The sixty five personalised learning reports available for analysis were a convenience sample i.e. they were the reports that were provided to, and retained by, the personal tutors on the PGCE course. Nineteen reports were not retained.

\subsection{Content Analysis of Data}

The reports were categorised on the basis of the child's SEN using the four broad categories of the SEN Code of Practice (CoP, DfES 2001) These four areas are: cognition and learning; behaviour, emotional and social development; communication and interaction, and; sensory and/or physical needs. Pupils were then placed into the further subdivisions provided, for example, hearing impairment or speech, language and communication needs (see Table 1). Decisions were made based on either explicit statements within the reports, for example, 'Harry has diagnosed speech, language and communication needs', or implicitly through descriptions used by, or for, the trainee. In the latter instance reports were re-read and subcategories assigned based on the description of a child's abilities and the targets identified in the child's individual education plan. There were 3 pupils who were not categorised because the descriptions were insufficiently clear or because they appeared to have SEN that could fit into one of two subcategories. The Code of Practice categories were used as these were terms that were likely to be understood and used by class teachers 
Table 1. Categorization of personalized learning reports.

\begin{tabular}{lll}
\hline Cognition and learning needs & & \\
\hline Specific learning difficulties & Dyslexia & 5 \\
Moderate learning difficulty & General learning delay & KS1 18 16 \\
& & 4 \\
Severe learning difficulties multiple & Medical & 3 \\
Profound and multiple learning difficulty & Literacy -dyslexia & 5 all KS2 \\
& EBD/SE & 5 \\
Behavior, emotional and social development needs & & 4 \\
& ADHD & 2 \\
Communication and interaction needs & Autistic spectrum disorder & 4 \\
Sensory and physical needs & Speech, language and communication needs & 1 \\
& Visual impairment & \\
& Hearing impairment & 3 \\
\hline
\end{tabular}

Note the range of pupils with SEN that trainees are enabled to work with.

\subsection{Discussion - why have students made these choices?}

Students were instructed to select a child who they could help to learn and from whom they could learn. A number of factors will have been layered on to the final 'choice' - not least of all the preferences of the staff (based on knowledge of the individual child's needs and support). In addition decisions may have been determined by the prevalence of certain 'categories of special educational need' both in terms of relative high frequency, for example for emotionalbehavioral difficulties and for relatively rare physical conditions. Another influencing factor might include the degree of generalizability of the child's difficulties. Thus, for example, students would anticipate that they may work with a child who has emotional and behavioral difficulties or who is on the autistic spectrum but may not encounter a child who is severely deaf.

\subsubsection{Framing of the Task}

The task asked students to focus on one subject or area. This is likely to have skewed the child chosen for the report and resulted in a focus on literacy and numeracy as these are the keys to the wider curriculum and schools are required to very closely monitor pupil progress in these areas.

\subsubsection{Role of the School and Its Understanding of SEN}

The dominant culture and expertise within schools will have contributed to the decision about which child would be suitable for study but, as importantly, this culture will have impacted upon the information available to trainees. Thus detailed data are held on each child in relation to progress in literacy and numeracy through high stakes testing where there are considerable pressures on schools to demonstrate certain levels of attainment. In order to ensure that standards are achieved a very highly prescribed curriculum and pedagogy has been developed particularly in literacy in the Foundation Stage (3-5 year olds) and Key Stage 1 (5-7 year olds) (Rose, 2006). This prescription enables practitioners to recognise individuals whose development falls below expectations and so these pupils can then be readily identified as having special educational needs. Once recognised the pupils will then be equipped with an individual education plan with targets that then reflect this more highly specified curriculum. By way of contrast very little information may be recorded, for example, detailing a child's social skills or friendship groups and the attendant curriculum and assessment of these areas is much less prescribed and therefore less foregrounded in descriptions of children with SEN.

The trainees will also have influenced the choice of pupil for study and each will have come to their placement schools with their own personal and cultural view of what SEN means. These individual perspectives in turn, however, will be altered partly as a result of the collective experience of being placed in a particular school. The trainee is responsible for the content of the final report although it is acknowledged that their analysis will reflect the views of the teachers, teaching assistants and SENCOs with whom they worked.

\subsubsection{Pupils Identified with SLCN}

An initial reading of all of the reports revealed that only 4 children were categorized as having specific SLCN thus few trainees have direct experience of working with these pupils despite prevalence figures of 7.4\% (Tomblin, 1997). A number of factors may account for the low levels of pupils with SLCN encountered one of which might be that these children are not being identified echoing the findings of The Communication Trust (2013). It is also possible that 
children with SLCN are not used for this task because they already receive a detailed program of support or because their very specific needs may not afford opportunities for generalization to other pupils with SEN. Furthermore it is possible that due to the trainees' prior experience in preparing a speaking and listening profile they may perceive a focus on SLCN as potential duplication.

\subsection{Close Analysis of 'Literacy' Subset of Reports: Background}

As part of the initial categorization of pupils' SEN there was a significant proportion of children $(\mathrm{n}=34)$ who were placed in 'Cognition and Learning: Moderate learning difficulties'. This categorization was arrived at mostly through reference to a blend of explicit (based on levels of attainment achieved) and implicit information provided by the trainee in the report; no child was labelled 'has moderate learning difficulties'. Thus, for example, David aged 6 is, 'struggling in most areas and is still working towards his early learning goals' (these are levels that children would be expected to reach by the end of their first formal year of schooling, age 5); [He needs to work on his] 'basic skills recognising letters and number correspondences; recognise and read simple CVC (consonant vowel consonant) words in context'.

The Department for Education and Skills in 2003 stated that MLD is the largest group of children with special educational needs and is one where there is potential overlap with other categories and that clarity of definition is needed. Pupils with moderate learning difficulties "have much greater difficulty than their peers in acquiring basic literacy and numeracy skills and in understanding concepts. They may also have associated speech and language delay, low self-esteem, low levels of concentration and under-developed social skills." (DfE, 2011). This definition was used in order to confirm whether a particular child was most accurately assigned to the MLD group based on a cluster of descriptions. One of the unifying factors within this relatively disparate group was the prevalence of comments related to difficulties in literacy. This group was then of immediate interest due to the links between language development and literacy learning and the reports were analyzed with a view to answering the question 'what do trainees' descriptions of literacy reveal about their understanding of speech, language and communication?' In order to address this question, an exploratory hypothesis-testing approach was adopted, anticipating reference to speech, language and communication in the reports, because the children had been described in terms of their literacy development (and most often specifically reading). I was also interested in whether there had been any specific consideration of whether the child's literacy difficulties may have been linked to their spoken and receptive language development. The model currently used to explain reading development in England has been the Simple View of Reading (Gough and Tunmer, 1986), which explicitly refers to language comprehension as one aspect of reading development and determines that 'reading comprehension $=$ word recognition $\mathrm{x}$ language comprehension'. The currency of this particular model might lead teachers to more clearly recognize the role of spoken language in the development of reading.

\subsubsection{Sampling of Subset}

A purposive sampling approach was adopted (Cohen, Mannion \& Marrion, 2003) where only those pupils categorized as within the MLD group were considered for further analysis. Furthermore, within the original sample of 34 I decided to exclude Key Stage 2 pupils ( 8 to 11 year olds, $n=16$ ) and to focus the analysis only on Key Stage 1 (5-7 year olds, $n=$ 18). This decision was taken as research strongly supports links between early language delay and/ disorder and later literacy difficulties (Arkkila et al, 2008; Beitchman et al, 1996 Conti-Ramsden \& Durkin, 2008) and therefore it was anticipated that this subgroup would be most fruitful in terms of what students' descriptions of literacy revealed about their understanding of speech, language and communication.

\subsubsection{Analysis of the Reports}

The reports could be viewed as a simple form of temporal narrative (Mishler, 1995) resulting from the writing frame's structure (see Appendix 2). The first section of the report consisted of: a historical view of the child from the school's perspective; the child's 'presentation' at school including strengths and difficulties in a subject; support and barriers to learning and current targets. The second section of the report demands more reflection from the trainees and provides the following headings: how the trainee planned and undertook work with the pupil; their evaluation of the intervention that took place, and, future recommendations.

It is important to acknowledge that my analysis of the reports is framed by a number of underlying constructs. First, the current policy context in SEN includes a major focus on speech, language and communication skills for all pupils (Communication Trust, 2013) and for those with identified SLCN (Bercow, 2008). Secondly, I am viewing each trainee's descriptions of literacy, with or without reference to speech, language and communication, as indicative of the teacher's and teaching assistant's awareness of these aspects because the task is mediated by school personnel. Finally, I acknowledge that, as a former speech and language therapist, my analysis is conceptualized within a framework which emphasizes the importance of spoken and receptive language as a major contributor to the development of reading whilst acknowledging that perceptual and spatial skills also play a significant role (Goswami and Bryant, 2010). 


\subsubsection{How the Analysis was Carried Out}

Coding was carried out on an iterative basis in which the robustness of the coding was tested through 'second look' (Crabtree and Miller, 1992) The content of each report was analyzed in relation to the outline prompts of the writing frame (see below) and where possible relevant information was placed under each of these headings. The initial coding of reports sought to determine whether literacy was indeed a factor in the categorization into moderate learning difficulties, based on whether it was the main focus of the current individual education plan and the main focus of the trainee's intervention (see Table 1).

Of the eighteen interventions described fourteen were focused on literacy (four chose to focus on numeracy) where literacy includes reading, writing, handwriting and phonics (which encompasses both reading and writing). Handwriting is included as part of literacy based on more recent understandings of its role in contributing to the composition process in writing (Medwell and Wray, 2007). Within the fourteen literacy interventions ten explicitly referred to the teaching of phonics and two of the fourteen reports focused on a phonics-only intervention. Each of the texts was recursively viewed using a deductive process through a number of different lenses which were: reference to speech, language and communication (strengths and difficulties); interaction; and additional information that might indicate an underlying difficulty with language such as concentration or attention. The coding categories are summarized in Table 2 and an example of coded information from one report is provided in Table 3.

Table 2. Coding categories used in the personalized learning reports

\begin{tabular}{ll}
\hline Description & Code \\
\hline Speech language or communication described as a difficulty & pink \\
Speech language communication mentioned as a strength & green \\
Additional unprompted reference to aspects that may relate to development of speech, language and & blue \\
communication e.g. concentration & italics \\
Interaction mentioned & yellow highlighting \\
Confusion in description of speech, language and communication & \\
\hline
\end{tabular}

Table 3. Example coding of one personalized learning report

\begin{tabular}{|c|c|}
\hline Child ID & GG (Male) \\
\hline $\begin{array}{l}\text { Background information on the child - } \\
\text { (edited to focus on school-based, rather } \\
\text { than home-based, content) }\end{array}$ & $\begin{array}{l}\text { Poor reader and writer } \\
\text { GG in the lower ability group for numeracy and literacy }\end{array}$ \\
\hline Description of literacy & Talks about reading first after Numeracy mentioned as a problem (but not specific) \\
\hline Strengths and Difficulties & His enthusiasm and his spoken language and some reading ability improved here by his interest \\
\hline & $\begin{array}{l}\text { D GG's writing is fairly poor for his age GG's writing also suffers greatly from disorganisation } \\
\text { and some technical accuracies esp. spelling } \\
\mathrm{D} * \text { misconceptions spoken English is reasonably clear but his word formation can become } \\
\text { 'mumbling' when he is reading in an unfamiliar setting. } \\
\text { D difficulty in concentrating in numeracy explanation } \\
\text { if is engaged can be an active participant in whole class sessions and contributions are amongst } \\
\text { the top } 5 \text { in the class }\end{array}$ \\
\hline $\begin{array}{l}\text { Current factors supporting learning and } \\
\text { barriers to learning }\end{array}$ & Guided Reading x 4 per week (when possible supported by teacher / student teacher) \\
\hline $\begin{array}{l}\text { Previous and current provision to } \\
\text { support pupil }\end{array}$ & $\begin{array}{l}\text { School Action for reading difficulties } \\
\text { Also attends Read Write Inc. group (phonics activities) }\end{array}$ \\
\hline $\begin{array}{l}\text { Current Individual Education Plan and } \\
\text { targets }\end{array}$ & $\begin{array}{l}\text { Develop phonetics } \\
\text { Sight vocabulary and Decoding } \\
\text { To move up a level by showing signs of phonetic development and Comprehension }\end{array}$ \\
\hline $\begin{array}{l}\text { Trainee's focus } \\
\text { 'How I undertook work with the pupil' }\end{array}$ & Focused on phonics \\
\hline $\begin{array}{l}\text { Summary evaluation of the } \\
\text { intervention that took place }\end{array}$ & $\begin{array}{l}\text { Reference to guided reading } \\
\text { His comprehension and response is now one of the best in the group, whilst this may just } \\
\text { reflect that } G G \text { has warmed to me over the placement rather than as a result of the strategies } \\
\text { put in place, it is still an encouraging sign. }\end{array}$ \\
\hline
\end{tabular}




\section{Results of Analysis of KS1 Literacy Reports}

\subsection{Over-arching Questions}

Four questions are asked of the KS1 'literacy' group reports $(\mathrm{n}=18)$ : what do the reports reveal about trainees' knowledge of speech, language and communication; was any specific link made between pupils' difficulties in literacy and their speech, language and communication skills; what recognition is given to the role of teacher-pupil interaction in the development of the children with literacy difficulties, and, finally, to what extent does the task design support trainees in referring to knowledge about speech, language and communication?

3.1.1 What do the Reports Reveal about Trainees' Knowledge of Speech, Language and Communication?

The results demonstrated the following frequencies of coded comments from 18 reports (see Table 4).

Table 4. Number of reports where aspects of coding referred to mentioned (and number of overall comments related to this category).

\begin{tabular}{|c|c|c|}
\hline Description & Code & $\begin{array}{l}\text { Number of reports where mentioned (and } \\
\text { number of comments related to this category) }\end{array}$ \\
\hline Speech language or communication described as a difficulty & pink & $5(10)$ \\
\hline Speech language communication mentioned as a strength & green & $10(18)$ \\
\hline Reference to expressive language & & $10(15)$ \\
\hline Reference to receptive language & & $5(8)$ \\
\hline $\begin{array}{l}\text { Additional reference to aspects that may relate to development } \\
\text { of speech, language and communication e.g. concentration }\end{array}$ & blue & $10(11)$ \\
\hline Interaction mentioned & italics & $2(3)$ \\
\hline $\begin{array}{l}\text { Confusion in description of speech, language and } \\
\text { communication - }\end{array}$ & $\begin{array}{l}\text { yellow } \\
\text { highlighting }\end{array}$ & $2(2)$ \\
\hline
\end{tabular}

More reference is made to expressive language rather than receptive language (see Figure 1). Of these 15 comments, 13 related to strengths in expressive language and 2 to difficulties with expression. Receptive language was referred to less frequently (only in 5 reports) and usually in terms of difficulty ( 6 references) rather than strengths ( 2 references). The reports provided by trainees present expressive language as the ability to express ideas (usually in relation to this being a requirement for writing) and opinions, to contribute and to have a good range of vocabulary. Receptive language was presented as the ability to develop an understanding of vocabulary; to retain and follow instructions and to listen to others. The rare references to 'communication' focused on being able to be an effective or good communicator in a range of contexts, for example with both children and adults alike. The issue of 'speech' was seldom referred to and this is understandable given both the age range of pupils (5-7 year olds) who would have developed appropriate enunciation of speech sounds.

One of the key findings from the analysis was the lack of clarity when describing a child's spoken receptive and expressive language skills; for example one trainee described 'spoken language as reasonably clear but word formation can become mumbling when reading in an unfamiliar setting' thus confusing a reading aloud skill with a spoken language skill. Similarly another trainee recorded that a child 'can speak good English when reading'. One of the trainees demonstrated confusion around the issue of the difficulties encountered by a child speaking English as an additional language (EAL) and it was not clear whether the child also had an underlying expressive language delay.

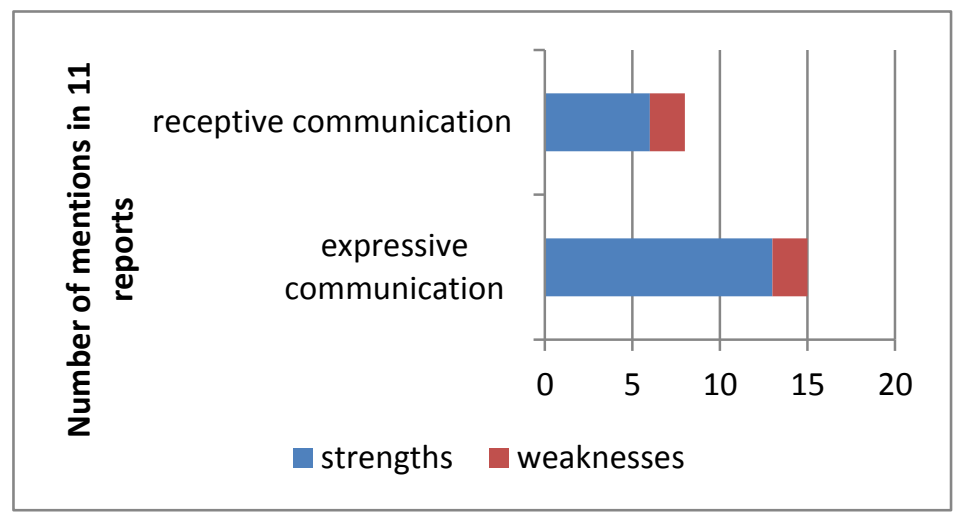

Figure 1. Expressive and Receptive Communication Summary 
Trainees spontaneously (i.e. without prompts) made reference to attention and concentration in 10 reports; 1 of which was a strength- 'James is attentive'. The remaining 9 comments described the children's difficulties in these areas and how they were a barrier to learning; for example, 'easily distracted and lacks concentration', 'Jack needs to be refocused several times and often requires adult support to keep him on task.'

3.1.2 Was Any Specific Link Made between Pupils' Difficulties in Literacy and Their Speech, Language and Communication Skills?

There was no specific reference to links between speech, language and communication and literacy development even when, for example, a speech and language therapist was involved in creating the program of work for the child. There were, however, in thirteen of the eighteen reports detailed descriptions of how the child was struggling with phonics and/ or the detailed steps being made to address this. Thus for example Jack, aged 6 is described as 'finding difficulty with the recognition of final sounds within CVC words, as well as struggling in recognizing, saying and blending the vowel sounds in CVC words'.

\subsubsection{What Recognition is Given to the Role of Teacher - Pupil Interaction in the Reports of the KS1 Literacy Group?}

There was no evidence within the reports that any specific action had been taken to address teacher-pupil interaction neither within the historical information provided or within the work undertaken by the trainees. Two reports made reference to social interaction; for Beatrice both a strength 'communicates and works with the child and her Learning Support Assistant' and a difficulty was identified 'she doesn't communicate well with many of the children in the class' and for a second child GG the report states that 'GG has warmed to me over the placement'.

3.1.4 To What Extent Does the Task Design Support Trainees in Referring to Knowledge about Speech, Language and Communication?

Of the 18 reports analyzed, 10 trainees made very explicit reference to the writing frame and had structured their text in accordance with the prompts provided. Of the remaining reports it was possible to broadly categorize information under the main headings, although there were one or two reports where the clarity of the writing made this more difficult. The writing frame offered to trainees can largely be seen to be helpful in general terms as the majority of trainees who used these prompts supplied more detailed information. Individuals who didn't explicitly use the framework generally produced shorter, less detailed reports. Most references to speech, language and communication could have occurred in response to the specific prompts provided in the checklist (appendix 1) such as 'expressive and receptive communication and language competence' and more rarely in response to 'social skills and interaction with others'. Few comments in relation to speech and language and communication necessarily occurred spontaneously.

\section{Discussion}

The discussion is structured within two subheadings. First, what do trainees appear to understand or not understand in relation to speech, language and communication in literacy? This subsumes the questions: what do the reports reveal about trainees' knowledge of speech, language and communication; was any specific link made between child's difficulties in literacy and their speech language and communication skills; what recognition is given to the role of teacher -pupil interaction in the development of the children with literacy difficulties? The second aspect considers how the task constrains or offers affordances to trainees in demonstrating knowledge about pupils' speech, language and communication and discusses potential solutions to any limitations found.

\subsection{What do Trainees Appear to Understand or not Understand in Relation to Speech, Language and Communication in Literacy?}

Ten trainees included references to expressive language in their descriptions of children with literacy difficulties. Fewer comments were made about receptive language which reflects general levels of awareness in the teaching profession (Mroz, Hall, Santer \& Letts 2001). It should be noted that no reports routinely included a breadth of information about speech, language and communication encompassing information about vocabulary, grammar, the ability to use language for a variety of purposes, such as hypothesis or summary and with different audiences. This is of concern due to the central role of language in all learning and particularly in the learning of literacy (Goswami and Bryant, 2010). The reports can be viewed as representative of the trainees' perceptions as they were specifically asked to integrate information from their data gathering and thus one can conclude from these findings that issues of speech, language and communication were not foregrounded in the trainees' minds. Since the task is heavily reliant on teacher-mentor support it is likely that these issues are also 'off or below the radar' for these colleagues who have potentially played a pivotal role in developing trainees' understandings of pupils with SEN.

The confusions expressed by trainees in trying to describe pupils' expressive and receptive verbal language and the misunderstandings around reading and spoken language skills are especially worrying given the trainees' previous assignment which specifically required them to produce separate profiles on speaking and listening and reading whilst 
demonstrating an understanding of the links between the two. Teacher-mentors were provided with copies of the personalized learning reports but not explicitly asked to comment; this is an issue which could be addressed and thus potentially clarify trainees' knowledge of speech, language and communication.

The trainees' reports had not made clear links between the speech, language and communication of an individual and their proficiency in literacy. Perhaps trainees consider the links to be so transparent that they felt no need to re-state them or the SEN status of the child highlights issues around teachers' perceptions that they lack the necessary 'skill set' to teach these particular children. Alternatively it may be that the close interweaving of literacy and spoken and receptive language skills is not explicitly understood and articulated amongst the teaching profession as Ellis \& Briggs, propose, "how language works in the world, how it develops and how it might be taught is something that should be part of teacher education" (2011 p. 277).

There was also little evidence that the role of teacher-pupil interaction in the development of the children with literacy difficulties was foregrounded as the results show only 3 comments over 2 reports. This absence could be explained in part due to the performative nature of the individual education plan written for pupils with SEN with an emphasis on very specific and measurable targets. Thus, whilst teachers might be very mindful of the importance of pupils' interactions and relationships with themselves and with their peers, the social semiotics of the classroom (Hodgkinson, 2004) does not foreground these concerns, rather focusing on curriculum outcomes in a context focused on assessment. However it is disappointing and startling that a key strategy in a teacher's skills set, the repertoire of dialogic behaviors known to inform learning and teaching, is not specifically capitalized on in the education of a child with SEN. Thus within the writing frame's historical context and the current intervention there were no specific references to how, for example, scaffolded dialogue, including careful use of questioning, might be exploited in order to address the child's needs.

\subsection{To What Extent does the Task Design Support or Hinder Trainees in Referring to Speech, Language and Communication?}

It appears that the structure of the task with its emphasis on development in a subject might not be conducive to considering broader issues that relate to all learning, such as a child's understanding of and use of spoken language. It is recognized that because communication skills are so central to us as human beings that they are often taken for granted (The Communication Trust, 2013). This focus on one subject is pragmatic, as limited time is available to consider one pupil and the task is designed for both secondary trainees, who teach only specific subjects in addition to primary trainees who teach all. Secondly the task may also be heavily influenced by the 'standards agenda' with its concentration on results within subjects, such as reading and writing, within the curriculum for English, rather than speaking and listening. This would explain the frequent references to phonics and phonics interventions in reading as there has been an ongoing determination to ensure all children are taught to read using a 'phonics first' approach with prescribed materials (Rose, 2006).

Analysis of the task and support materials (appendices 1 and 2) reveals a number of issues that might constrain trainees in referring to speech, language and communication. There is very little exposition of what meanings are ascribed to the terms within the 'checklist of environmental and pupil factors'. Thus, for example, what are trainees to understand by the terms 'expressive and receptive communication' and 'language competence'? Does the expressive language relate to reading aloud, could receptive language refer to understanding what you have read and does language competence refer to the child's skill in using English over any other languages they might employ? Within the task and support materials a glossary could be provided that succinctly defines key terminology. Further specific changes could be made to the pupil factors to address concerns about limited teacher knowledge of speech, language and communication. Trainee teachers' (and their mentors') knowledge of language development could be enhanced if this aspect of the checklist was further exemplified through expanded definitions with, for example, the length and complexity of utterance a child might be expected to produce and understand at a certain age and lists of key vocabulary that one might expect to use and understand. These 'norms' for speech, language and communication have already been produced by the Communication Trust in poster format and have been sent to all primary schools but limited opportunities restrict mentors' awareness (see Mroz, 2013).

A similar issue with uncertain definitions prevails in the 'environmental factors' section of the checklist; the terms 'teaching methods' and 'class management and relationships' are not explored. Significantly for this particular research there is no specific reference to teacher-pupil interaction. Classroom talk could potentially be recorded under 'teaching methods' or 'class management and relationships' although it would potentially have considerable, if different, contributions in both. The omission of classroom talk is curious given that trainees were encouraged to consider environmental influences on a child's progress - of which this would be a significant factor (Alexander, 2010, Ofsted, 2010). A more general adaptation to the 'environmental factors' might be to include aspects of the Communicative 
Environment Checklist (The Communication Trust , 2011) which would enable trainees to think carefully about how the environment supported or hindered communication, by, for example, focusing on noise levels, visual distractions and the complexity of language used to the children. In addition the content of the environmental checklist could be more explicit and reflect issues that are known to be significant in pupils' learning, such as classroom talk, including dialogic teaching. Prompts could be provided which might encourage teachers to reflect on, for example, the repertoire of talk used such as speculation, analysis, scaffolded instruction or exposition (see Alexander 2009, 2012 for a full explanation and discussion). These terms could be much more closely defined and exemplified so that teacher-pupil interaction was explicitly referred to in the interventions for pupils with SEN.

The personalised learning task could be more effectively aligned to address the following concerns: limited teacher knowledge and confidence of speech, language and communication; knowledge to work with children with SLCN, and, the embedding of teacher-pupil interaction and its central role in learning. A key useful change would be to introduce the task with the expectation that trainees were actively encouraged to seek evidence about a child's expressive and receptive language (regardless of the SEN described ) and the communicative environment in which learning was taking place. This shift in emphasis could ensure that the vital importance of teachers' ability to assess their pupils' language competence and their own use and adaptation of talk becomes embedded in all teaching and learning opportunities. A further benefit to the trainees would be that the 'new' task would afford an opportunity to explore the wealth of resources that are available from The Communication Trust in England. If 'protected time' was provided to trainees they could then research, critically evaluate and trial the materials and discuss this knowledge with their mentors (Mroz, 2013) with attendant benefits to the pupils, the schools and the trainees themselves.

Ultimately one can micro-manage the trainees' completion of the task using, for example, the most rigorous check lists. However if teacher-mentors are not enabled to consider that the speech, language and communication of a child are central to how and what they are taught, or if teachers have not been enabled to develop the underlying professional knowledge of pupils' language competence and their own role in its development, then the checklist itself is unlikely to impact on the reflections made by trainees. Indeed one could argue that such close control of the trainees' developing knowledge of SEN might simply be a further reflection and promotion of the performative culture (Ball, 2003) which is a significant influence in schools in England.

The role of the teacher-mentors in mediating this task is crucial at a much more fundamental level than of subject knowledge. Underlying all of the specific recommendations is the ability of teacher- mentors to be explicit about their own practice in relation to pupils with SEN and to openly reflect upon and critique how that practice has been developed and to enable it to be challenged. Eraut (2007) focuses on the role of such learning activities in the development of individuals early on in their career emphasizing the importance of questioning, reflection and learning from mistakes - all of which can be modelled and discussed by the teacher-mentor. Thus, for example, teachers might be encouraged to clearly summarize their knowledge of a child's language competence, with examples, in order to model to the trainee how they are reaching these conclusions and to acknowledge the limitations and biases that might prevail in their analysis. This is particularly challenging in a field where teachers acknowledge their own lack of expertise (Dockrell, 2001, OFSTED, 2012b) but where demonstration of competence is demanded (OFSTED, 2012a).

\section{Conclusions and Recommendations}

The analysis of this sub-set of personalised learning reports for pupils with SEN in literacy has indicated that pupils' skills in speech, language and communication are not routinely and comprehensively considered for each child and that no explicit links are made between these skills and the successful development of literacy. Furthermore, the task itself has not enabled trainees to explicitly consider the role of 'teacher-pupil interaction' in developing the pupil's literacy skills. The interventions referred to are often more focused, for example, on developing phonic knowledge but lack a broader acknowledgement and understanding of the language skills underlying literacy development.

The personalized learning task is intended to support PGCE students in their role as future teachers in inclusive settings. The task however, is a complex one and relies on knowledge of SEN and techniques of teaching and learning that trainees are still developing. The support from school and higher education institution staff is crucial to the depth of understanding achieved. The teachers' awareness of their own language as a vehicle for all learning (Alexander, 2009) and teacher - knowledge of the pupils' language competence will be significant factors in determining the future success of all social and learning interactions in the classroom. This combination of teaching skills will enable teachers and trainees to firstly acknowledge and then to support, children with specific and generalised SLCN. This identification and subsequent assistance will provide the key to real inclusion by "providing a framework within which all childrenregardless of ability, gender, language, ethnic or cultural origin - can be valued equally, treated with respect and provided with real opportunities at school." (Thomas and Loxley, 2007, p. 124). 


\section{References}

Alexander, R. J. (2008). 4th edition. Towards dialogic teaching: rethinking classroom talk. York: Dialogos.

Alexander, R. J. (editor and lead author) (2010). Children, their World, their Education: final report of the Cambridge Primary Review. London: Routledge.

Alexander, R. J. (2012). Improving Oracy and Classroom Talk in English Schools Achievements and challenges University of Cambridge Extended and referenced version of a presentation given at the DfE seminar on Oracy, the National Curriculum and Educational Standards, 20 February 2012. Retrieved from http://www.primaryreview.org.uk/downloads_/news/2012/02/2012_02_20DfE_oracy_Alexander.pdf 1/2/2013

Ball, S. (2003). The teacher's soul and the terrors of performativity Journal of Education Policy, 18(2), $215-228$. http://dx.doi.org/10.1080/0268093022000043065

Barnes, D. (1976). From Communication to Curriculum. Harmondsworth: Penguin.

Botting N., \& Conti-Ramsden, G. (2000). Social and behavioural difficulties in children with language impairment. Child Language, Teaching and Therapy, 16(2), 105-120. http://dx.doi.org/10.1191/026565900668565128

Clegg, J., Hollis, C., Mawhood, L., \& Rutter, M. (2005). Developmental language disorders - a follow-up in later adult life: Cognitive, language and psychosocial outcomes. Journal of Child Psychology and Psychiatry, 46(2), 128-149. http://dx.doi.org/10.1111/j.1469-7610.2004.00342.x

Cohen, L., Mannion, L., \& Morrison, K. (2005). Research Methods in Education. London: Taylor and Francis.

Conti-Ramsden, G., Knox, E., Botting, N., \& Simkin, Z. (2002). Educational placements and National Curriculum Key Stage 2 test outcomes of children with a history of specific language impairment. British Journal of Special Education, 29(2), 76-82. http://dx.doi.org/10.1111/1467-8527.00244

Conti-Ramsden, G., \& Durkin, K. (2008). Language and independence in adolescents with and without a history of specific language impairment (sli). Journal of Speech, Language and Hearing Research, 51(1), 70-83. http://dx.doi.org/10.1044/1092-4388(2008/005)

Crabtree, B. F., \& Miller, W. L. (1993). Doing Qualitative Research: Research methods for primary care, Volume 3 London: Sage.

Department for Children, Schools and Families. (2008a). The Bercow Report: a review of services for children and young people (0-19) with speech, language and communication needs. London: DCSF. Retrieved from www.dcsf.gov.uk/slcnaction/bercow-review.shtml. 1/12/2012

Department for Children, Schools and Families. (2008b). Better Communication: An action plan to improve services for children and young people with speech, language and communication needs. Nottingham: DCSF.

Department for Education. (2010). The Importance of Teaching: Schools White Paper London: DfE

Department for Education. (2011). The Green Paper Support and aspiration: A new approach to special educational needs and disability London: DfE.

Department for Education. (2012). The Teachers' Standards Retrieved from www.gov.uk/government/publications/teachersstandards 1/12/2012

Department for Education and Skills. (2001). Special educational needs: Code of practice. London: DfES.

Department for Education and Skills. (2006). 2020 Vision Report of the Teaching and Learning in 2020 Review Group London: DfES.

Dockrell, J. E., \& Lindsay, G. (2001). Children with specific speech and language difficulties - the teachers' perspective. Oxford Review of Education, 27(3), 369-394.

Dockrell, J. E., Ricketts, J., \& Lindsay, G. (2012). Understanding speech, language and communication needs: Profiles of need and Provision. Research Report DFE-RR247- BCRP4 London, DfE.

Eraut, M. (2007). Learning from other people in the workplace, Oxford Review of Education, 33(40), 403-422. http://dx.doi.org/10.1080/03054980701425706

Galton, M., Hargreaves, L., Comber, C., \& Wall, D. (1999). Inside the primary classroom: 20 years on. London: Routledge. http://dx.doi.org/10.4324/9780203269329

Goswami, U., \& Bryant, P. (2010). Children's cognitive development and learning. In Alexander R J, with Doddington C, Gray J, Hargreaves L and Kershner R (eds.) The Cambridge Primary Review Research Surveys. London: Routledge, pp.141-167 
Gough, P. B., \& Tunmer, W. E. (1986). Decoding, reading, and reading disability. Remedial and Special Education, 7, 610. http://dx.doi.org/10.1177/074193258600700104

Grainger, K. (2013). 'The daily grunt': Middle-class bias and vested interests in the 'Getting in Early' and 'Why Can't They Read?' reports. Language and Education, 27(2). 99-109. http://dx.doi.org/10.1080/09500782.2012.760583

Hartshome, M. (2006). Speech, Language and Communication Needs and Literacy Difficulties I CAN Talk Series, Issue 1. Retrieved from http://www.ican.org.uk/ /media/Ican2/Whats\%20the\%20Issue/Evidence/1\%20Communication\%20Disability\%20a nd\%20Literacy\%20Difficulties\%20pdf.ashx 1/11/2012

Hodgkinson, S. (2004). Naturalistic observation of small group work in Key Stage 1 classrooms. Part 1: The social semiotic landscape of the primary classroom. Paper presented at the Teaching and Learning Research Programme Annual Conference Papers, Cardiff, UK Retrieved from www.leeds.ac.uk/educol/documents/141934.htm $15 / 1 / 2014$

Law, J., Boyle, J., Harris, F., Harkness, A., \& Nye, C. (2000). International Journal of Language and Communication Disorders, 35(2), 165-188. http://dx.doi.org/10.1080/136828200247133

Lindsay, G., Dockrell, L., \& Strand, S. (2007). Longitudinal patterns of behaviour problems in children with specific speech and language difficulties: child and context factors. British Journal of Educational Psychology, 77(4), 811828. http://dx.doi.org/10.1348/000709906X171127

Lofthouse, R., \& Thomas, U. (2013). Mentoring student teachers in practice; developing an understanding of the architecture of mentoring, Paper presented at the European Practice-Based and Practitioner Research Conference on Learning and Instruction (EAPRIL) November, Switzerland.

Marzano, R. J., Pickering, D. J., \& Pollock, J. E. (2001). Classroom Instruction that Works. Research-Based Strategies for Increasing Student Achievement. Alexandria, VA: Association for Supervision and Curriculum Development.

Medwell, J., \& Wray, D. (2007). Handwriting: what do we know and what do we need to know? Literacy, 41(1), 10-15. http://dx.doi.org/10.1111/j.1467-9345.2007.00453.x

Mercer, N., Dawes, L., Littleton, K. \& Wegerif, R. (2010). Thinking Together Project Retrieved from http://thinkingtogether.educ.cam.ac.uk/ 23/7/2013

Meschi, E., Micklewright, J., Vignoles, A., \& Lindsay, G. (2012). The transitions between categories of special educational needs of pupils with Speech, Language and Communication Needs (SLCN) and Autism Spectrum Disorder (ASD) as they progress through the education system. Better Communication Research Programme. Retrieved from https://www.gov.uk/government/uploads/system/uploads/attachment_data/file/219626/DFE-RR247-BCRP11.pdf $23 / 7 / 2013$

Mishler, E. G. (1995). Models of narrative analysis: a typology. Journal of Narrative and Life History, 5, 87-123.

Mroz, M., Hall, E., Santer, J., \& Letts, C. (2002). Children's speech and language development: an investigation of the knowledge, skills and understanding of early years professionals. Report to the Nuffield Foundation. Newcastle upon Tyne: University of Newcastle upon Tyne, October.

Mroz, M. (2013). Pre-service teacher education and the inclusion of children with language delay and speech language communication needs: a case of 'tweaking' or re-thinking practice? Paper presented at the European Conference on Educational Research, 10-13 September, Istanbul

National Association for Schoolmasters and Union of Women Teachers. (2008). Special Educational Needs and Inclusion: Reflection and Renewal Birmingham: NASUWT

OFSTED. (2010). The Annual Report of Her Majesty's Chief Inspector of Education, Children's Services and Skills 2009/10.

Retrieved

from: www.ofsted.gov.uk/news/annual-report-of-her-majestys-chief-inspector-of-education-childrens-services-and-skills$20091030 / 3 / 2011$

OFSTED. (2011). The framework for the inspection of initial teacher education 2012. Retrieved from www.education.gov.uk/publications/standard/publicationDetail/Page1/110115 10/1/2013

OFSTED. (2012a). The framework for school inspection from January 2012. Retrieved from: www.ofsted.gov.uk/resources/framework-for-school-inspection-january-2012 10/1/2013

OFSTED. (2012b). From training to teaching early language and literacy London: OFSTED. Retrieved from 
http://dera.ioe.ac.uk/16029/1/From\%20training\%20to\%20teaching\%20early\%20language\%20and\%20literacy.pdf $10 / 1 / 2013$

Rose, J. (2006). Independent review of the teaching of early reading, Department for Education and Skills: London, DfES Retrieved from webarchive.nationalarchives.gov.uk/20130401151715/https://www.education.gov.uk/publications/eOrderingDownl oad/0201-2006pdf-EN-01.pdf 22/4/2012

Steer, A. (2009). Learning Behaviour: Lessons Learned - A Review of Behaviour Standards and Practices in our Schools London: DCSF. from http://webarchive.nationalarchives.gov.uk/20130401151715/https://www.education.gov.uk/publications/standard/_ arc_SOP/Page8/DCSF-00453-2009 17/2/2013

Stothard, S. E., Snowling, M. J., Bishop, D. V. M., Chipchase, B., \& Kaplan, C. A. (1998). Language impaired preschoolers: a follow up into adolescence. Journal of Speech, Language and Hearing Research, 41, 407-418.

The Communications trust. (2011). Primary milestones poster. Retrieved from: www.thecommunicationtrust.org.uk/media/1590/primary_milestone_poster_-_final.pdf 30/3/2012

The Communications trust. (2011). The Hello Campaign. (2011). Retrieved from www.thecommunicationtrust.org.uk/about-the-trust/what-is-the-hello-campaign.aspx 30/9/2011

The Communication Trust. (2013). A Generation Adrift: The case for speech, language and communication to take a central role in schools' policy and practice. London: The Communication Trust.

The Salamanca Framework and Statement for Action. (1994). Retrieved from www.unesco.de/fileadmin/medien/.../Salamanca_Declaration.pdf 17/2/2012

Teacher Development Agency. (2008, 2012). Special educational needs and disability training resources for PGCE programmes Framework for personalised learning. Retrieved from http://dera.ioe.ac.uk/13815/1/framework.pdf $1 / 6 / 2012$

Thomas, G., \& Loxley, A. (2007). Deconstructing Special Education and Constructing Inclusion. Second Edition, Milton Keynes, Open University Press,

Tomblin, J. B., Records, N. L., Buckwalter, P., Zhang, X., Smith, E., \& O’Brien, M. (1997). Prevalence of specific language impairment in kindergarten children. Journal of Speech, Language and Hearing Research, 40, 1245-1260.

Wedell, K. (1993). Special needs education: the next 25 years, in: National commission on Education, Briefings for the National Commission on Education London: Heinemann.

Wilkinson A. (1965). Spoken English, Birmingham, Birmingham University Press.

\section{Websites}

http://www.communicationhelppoint.org.uk/sitecore/content/Communication

Trust/Publications/ /media/Communication

http://www.dera.ioe.ac.uk/13814/1/taskbrief.pdf Task brief for trainees- Digital Education Resource Archive (DERA) retrieved 15/1/2013

www.education.gov.uk/.../glossary-of-special-educational-needs-sen-ter..website updated retrieved 12/2/2014

http://www.education.gov.uk/b00201451/sen-skills/sen-resources/personal-learning Retrieved 3/11/2012

http://www.education.exeter.ac.uk/projects.php?id=167 Framework for Personalised Learning. Retrieved 3/11/2012 
Appendix 1: a checklist of strengths and needs

\begin{tabular}{|l|l|l|l|l|l|}
\hline $\begin{array}{l}\text { Table 1: Checklist of } \\
\text { strengths and needs }\end{array}$ & \multicolumn{2}{|c|}{$\begin{array}{c}\text { Environmental } \\
\text { factors }\end{array}$} & \multicolumn{2}{c|}{ Pupil factors } \\
\hline & strengths & difficulties/needs & & strengths & difficulties/needs \\
\hline $\begin{array}{l}\text { School: } \\
\text { Appropriateness of: }\end{array}$ & & Sensory and motor functioning & & \\
\hline Curriculum, & & & Health/ conditions & \\
\hline Teaching methods & & Emotional state, self image & & \\
\hline $\begin{array}{l}\text { Classroom management and } \\
\text { relationships }\end{array}$ & & Motivation and interests & & \\
\hline $\begin{array}{l}\text { Home } \\
\text { Relationships with }\end{array}$ & & $\begin{array}{l}\text { Cognitive and intellectual functioning } \\
\text { immediate family }\end{array}$ & $\begin{array}{l}\text { Expressive and receptive } \\
\text { communication and language } \\
\text { competence }\end{array}$ & \\
\hline $\begin{array}{l}\text { Extended family } \\
\text { History of schooling, changes } \\
\text { of school etc. }\end{array}$ & & $\begin{array}{l}\text { Basic educational skills (literacy, } \\
\text { numeracy etc.) }\end{array}$ & \\
\hline Approaches ad styles of learning & $\begin{array}{l}\text { Social skills and interaction with } \\
\text { others }\end{array}$ & \\
\hline
\end{tabular}

Appendix 2: SEN Personalised Learning Task Report

Trainee name Date

PGCE course e.g. secondary history, primary mathematics

School name

Background information about the pupil

(gathered from pupil and school documentation, discussion with SENCO/class/subject teacher, observations)

Age: $\quad$ Gender:

Relevant past information (eg school attendance, previous specialist reports):

Strengths and difficulties (in the subject):

Current factors supporting learning and barriers to learning:

Current provision made to support this pupil:

\section{Current IEP targets (if appropriate) and relevant progress}

How were the recorded targets, approaches etc on the pupil's IEP being used? Was the pupil making progress towards these targets? What was the relevance of the setting to the pupil's progress in learning? eg where, when, with whom, teaching strategies used, resources used?

How you planned and undertook the work with the pupil 
Did you support learning broadly along the lines of the IEP targets or did you examine how the pupil's targets might be reviewed?

What did you do? What setting? How often? What teaching approaches/strategies did you use? From where did you gain your ideas for teaching? (eg SEN website, other websites, school materials, discussion with SENCO, reading) How did you monitor the pupil's progress? What records did you keep?

Evaluate the impact of the strategies you used on the pupil's progress against the target/s set. Discuss any difficulties you encountered in teaching and learning and the reasons for these.

\section{Conclusions}

What recommendations do you suggest for the next steps in teaching this pupil in this subject or age phase in the future? Give reasons for these.

What have you learned from the task - knowledge, understanding, skills, attitudes?

How can you transfer this knowledge into whole class teaching?

\section{$(\mathrm{cc}) \mathrm{BY}$}

This work is licensed under a Creative Commons Attribution 3.0 License. 